\title{
A educação ambiental pelas lentes do cinema documentário
}

\author{
Environmental education \\ through the lenses of documentary cinema
}

Fabiana de Amorim Marcello ${ }^{1}$. Daniela Ripoll ${ }^{2}$

Resumo: O número de produções cinematográficas destinadas a mostrar o esplendor, a abundância (e também a fúria) da natureza, bem como aquelas que evidenciam seu fim iminente parece, cada vez mais, ganhar visibilidade. Tomando como mote de análise o filme-documentário, nosso objetivo é problematizar as estratégias de linguagem operadas em alguns materiais para falar sobre educação ambiental - seja para ensiná-la, para defendê-la ou para fazer dela alvo de comoção. Metodologicamente, analisamos dois documentários: Uma verdade inconveniente e Lixo extraordinário. Neles, buscamos caracterizar os 'regimes de credibilidade', atentando para as estratégias ali estabelecidas e que, com efeito, contribuem para a construção do verídico. Tais documentários operam por meio de duas lógicas: (1) a de que a degradação ambiental faz-se associada à degradação humana (lógica construída a partir de uma 'gramática do catastrofismo'); (2) a da 'retórica do otimismo sustentável' (pela exibição de experiências ecologicamente sustentáveis).

Palavras-chave: Educação ambiental. Cinema. Documentário. Meio ambiente.

\begin{abstract}
The number of film productions designed to show the splendor, abundance (and fury) of nature, as well as those that show its imminent demise, seems to be gaining increasing visibility. Taking as an analysis theme the documentary-film, our intention was to discuss language strategies operating in some materials about environmental education - to teach it, defend it or target it as a dilemma. We analyzed methodologically two documentaries: An inconvenient truth and Waste Land. We sought to characterize the 'credibility schemes', paying attention to the strategies established by them and that, indeed, contribute to the construction of the truth. These documentaries operate through two logics: (1) environmental degradation is associated with human degradation (a logic built from a 'grammar of catastrophism'); (2) the 'rhetoric of sustainable optimism' (by the display of ecologically sustainable experiences).
\end{abstract}

Keywords: Environmental education. Cinema. Documentary. Environment.

\footnotetext{
${ }^{1}$ Universidade Federal do Rio Grande do Sul (UFGRS), Programa de Pós-graduação em Educação, Porto Alegre, RS, Brasil. E-mail: <famarcello@gmail.com>.

${ }^{2}$ Universidade Luterana do Brasil, Programa de Pós-graduação em Educação, Canoas, RS, Brasil.
} 


\section{Introdução}

A cada ano, o número de produções cinematográficas destinadas a mostrar o esplendor, a abundância (e, em alguns casos, também a fúria) da natureza em seu 'estado puro', bem como, mais recentemente, aquelas que evidenciam seu fim iminente parece, cada vez mais, ganhar visibilidade e, mais do que isso, se multiplicar. Comparativamente, no entanto, esta crescente produção cinematográfica encontra-se ainda, de algum modo, pouco explorada (ou, pelo menos, pouco divulgada), tal como afirma Guimarães e Guido (2013, p. 7), quando se pergunta sobre as razões pelas quais "o cinema e as produções audiovisuais em geral (vídeos, programas televisivos, videoclipes) têm sido pouco estudados no campo da pesquisa em educação ambiental". Um levantamento realizado em três dos periódicos mais expressivos da área de ciência e educação ${ }^{3}$ indica que, nos últimos seis anos (2010-2015), foram publicados apenas quatro artigos com a temática do cinema. Isso se torna ainda mais curioso quando sabemos que, em grande medida, o cinema é um material não apenas produtivo, como largamente utilizado nas escolas para a formação de crianças e jovens no que diz respeito ao tema da natureza.

Ainda que possamos afirmar que seja relativamente tímida a produção acadêmica em relação ao vasto universo de materiais fílmicos sobre as imagens da natureza (em suas mais diversificadas abordagens), Cerqueira e Aguiar (2013, p. 121) apontam que, basicamente, ela se vê inscrita em três linhas de interesse principais: uma, primeira, ligada aos filmes-documentário que, geralmente, envolvem o mundo natural e aquele dos desastres ambientais e, com efeito, vão da 'sacralização ao apocalipse'; uma segunda, que seria aquela sobre filmes que assumem como tema questões 'ambientalistas', frequentemente tomando seus protagonistas como 'defensores da natureza' (tal como o já popular Erin Brockovich) e, por fim, aqueles de animação, nos quais se 'opera representações simbólicas das visões humanas sobre a natureza'.

\footnotetext{
${ }^{3}$ Ainda que um pouco extensa, a organização deste levantamento merece receber algum detalhamento. O levantamento foi realizado com base nos resumos dos artigos publicados entre 2010-2015, nos seguintes periódicos: Ciência e Educação (22 edições), Revista Brasileira de Pesquisa em Educação e Ciências (16 edições) e, por fim, a revista Ensaio Pesquisa em Educação e Ciências (16 edições). No primeiro deles, constata-se a presença significativa de textos que têm como objeto de análise o livro didático (14 artigos), bem como aqueles que assumem a mídia ou mesmo outros artefatos mais variados da cultura como eixo central de debate (tais como materiais/revistas de divulgação científica, histórias em quadrinhos, novas tecnologias, museus, teatros escolares) (17 artigos no total). Aqui, a fotografia e a literatura também têm representado uma amostra tímida, com dois artigos de cada campo. Neste periódico, apenas dois artigos têm o cinema como foco de análise (e, mesmo assim, um deles toma o cinema não como central, mas como um dos elementos de composição argumentativa). No segundo periódico, a análise dos livros didáticos assume expressão relativa ( 6 artigos), já aqueles relacionados ao agrupamento dos variados artefatos da cultura - inclusive, neste caso, com a presença de análises de folders, e outros recursos da internet, como redes sociais (Orkut) e jogos (RPG) - se fazem mais abundantes (10 artigos). Neste periódico ainda, merece ser ressaltado que, em sua grande maioria, a análise se volta, mais uma vez, para revistas de divulgação científica. A análise de materiais de cunho literário percorre três artigos e nenhum deles tem como foco central a fotografia ou o cinema. Por fim, no terceiro periódico, a análise de livros didáticos se faz presente (oito títulos). Quanto aos artefatos variados da cultura (somando-se, inclusive, web-rádio e telejornais), 12 artigos os elegem como tema de análise. A fotografia e a literatura são representadas, cada uma, por um artigo. Quanto ao cinema, dois artigos o têm como foco de investigação. Finalmente, duas considerações merecem ser feitas sobre este levantamento: a primeira é de que assumimos apenas os artigos publicados (e não as resenhas); em seguida, que consideramos apenas os textos que, de fato, analisam diretamente os materiais na qualidade de corpus empírico (e não aqueles que se valem destes produtos no contexto escolar/pedagógico; neste caso, entendemos que a análise se refere, mais propriamente, às práticas pedagógicas em si mesmas).
} 
De algum modo, e tendo em vista estas considerações, este trabalho volta-se para a discussão sobre uma produção cinematográfica singular, que se enquadraria, então, na primeira linha de análise apontada por Cerqueira e Aguiar (2013), ainda que com variações em relação ao modo como os filmes-documentários são organizados, como veremos a seguir. Mais propriamente, voltamos nosso olhar sobre o papel do cinema-documentário na promoção de ações de educação ambiental direcionadas, direta ou indiretamente, ao desenvolvimento sustentável. Nesta condição, este texto está orientado pelas seguintes perguntas: que estratégias as produções filmográficas de cunho documental têm sugerido para a promoção da sustentabilidade? Podemos admitir que, tal como apresentados, incide nestes materiais uma 'pedagogia da imagem'? Tomando como mote de análise o filme-documentário, nosso objetivo está radicado, então, na problematização das estratégias de linguagem operadas nos filmes para falar sobre educação ambiental, seja para ensiná-la, para defendê-la, para estimulá-la ou mesmo para, junto a tudo isso, fazer dela alvo de comoção.

Para tanto, metodologicamente, serão analisados dois documentários comumente utilizados para pensar e mesmo para promover a chamada 'consciência ecológica': o mundialmente conhecido Uma verdade inconveniente ${ }^{4}$ (2006), protagonizado pelo ex-vice presidente americano $\mathrm{Al}$ Gore, e Lixo extraordinário ${ }^{5}$ (2010). Nossas escolhas não são aleatórias: por mais diferentes que sejam entre si (considerando suas propostas, linguagens e endereçamentos), ainda hoje, estes dois documentários podem ser tomados como materiais 'emblemáticos' e bastante singulares de exploração do tema da natureza. De um lado, não por acaso, mesmo passados quase dez anos de Uma verdade inconveniente, ele ainda é alvo de calorosas discussões, até mesmo na chamada 'grande mídia', servindo de base para o debate mais amplo sobre o meio ambiente e sua preservação (GONZALEZ, 2015) - sendo tomado, inclusive, como uma espécie de 'parâmetro' para outras produções semelhantes (EX-JORNALISTA..., 2015). De outro lado, Lixo extraordinário é um dos filmes que, sucessivamente, tem sido alvo de leituras diversas, geralmente no campo da comunicação, das artes visuais e da estética, já que retrata o universo de um artista (Vik Muniz), e seu processo de criação. Exatamente por isso, nossa opção foi trazer este material para as discussões do campo da educação ambiental, buscando nos inscrever, assim, no amplo debate travado no marco de uma não separação entre arte e ciência - mas, mais do que isso, indicando que, neste caso, é justamente por operar 'entre' as duas categorias que as estratégias de convencimento fazem-se mais sedutoras.

Para dar conta destas questões, este texto está organizado da seguinte forma: inicialmente, buscamos desenvolver duas discussões fundamentais, considerando o escopo do artigo: aquela que envolve traçar um percurso sobre como, de maneira mais ampla, tem sido analisada a retórica do desenvolvimento sustentável em materiais midiáticos; bem como aquela que procede a uma problematização sobre a linguagem própria do cinema-documentário (na qualidade de campo imagético sobre o qual nossas análises se sustentam). Em seguida, encaminhamos a análise dos dois filmes, apresentando as estratégias discursivas empregadas pelo cinema-documental nos produtos escolhidos, ou seja, indicando de que forma eles se organizam para a produção de

\footnotetext{
4 Título original: An inconvenient truth.

${ }^{5}$ Título original: Waste land.
} 
certas 'verdades' acerca da preservação do meio ambiente, da situação do planeta e, sobretudo, do nosso papel, individual e coletivo, frente a isso. Analiticamente, então, a proposta é que nos voltemos para estes documentários, desdobrando metodologicamente as perguntas acima mencionadas em outras: como estas duas produções se inserem num contexto de aprendizagem sobre a sustentabilidade? De que modo pretendem capturar e, de alguma maneira, educar o espectador, criando, para tanto, um contexto particular para a discussão sobre a sustentabilidade?

\section{Sustentabilidade e mídia: notas de uma breve revisão}

De acordo com Pereira (2010, p. 92), o chamado 'desenvolvimento sustentável' está na ordem do dia - e isso em termos midiáticos e em termos ambientais e corporativos (já que ele passou a ser o discurso padrão das organizações). Além disso, Pereira (2010, p. 92) afirma que o "desenvolvimento sustentável" - tido, de maneira ampla, como "aquele que atende às necessidades de presente sem comprometer a capacidade de as gerações futuras satisfazerem suas próprias necessidades" - virou 'moda' e sustenta parte da engrenagem da produção e do consumo na sociedade do espetáculo contemporânea, através, por exemplo, de vídeodocumentários (tal como o próprio Uma verdade inconveniente mencionado pela autora e tomado por ela como foco de análise) e de megaeventos com ampla cobertura publicitária mundial (como o Live Earth, também iniciativa do ex-vice-presidente dos Estados Unidos Al Gore).

Ainda de acordo com a autora, as preocupações ecológicas envolvendo a sustentabilidade emergem de modo organizado nos anos $1970^{6}$, mas se tornam mais visíveis no final dos anos 1980 - notadamente, em um relatório ${ }^{7}$ da Comissão Mundial sobre Meio Ambiente e Desenvolvimento das Nações Unidas, intitulado Nosso futuro comum (UNITED NATIONS, 1987) e, posteriormente, nas muitas Conferências fartamente noticiadas pela mídia a partir dos anos 1990 (a Rio 92, a Kyoto 97, a Estocolmo 2001 etc.). Preocupações envolvendo a ação antrópica sobre o aquecimento global e a perda da biodiversidade - temas diretamente vinculados ao desenvolvimento sustentável - começaram a ser veiculadas nos meios de comunicação, motivadas por cientistas de diferentes áreas do conhecimento, pelos movimentos ambientalistas, por organizações não governamentais de defesa da natureza etc.

No Brasil, esta produção se mostra evidente por meio de alguns materiais produzidos em canal aberto e voltados para este fim. Quanto a isso, Andrade (2003) discute como se operou a migração (e, neste sentido, também a transmutação, a hibridação) dos debates ambientais para a mídia em nosso país. Ao discutir sobre programas como Amaral Netto, repórter e Brasil, terra da gente (1969-1984) e, ainda, mais recentemente, Globo ecologia (no ar desde 1990), o autor nos mostra deslocamentos importantes (inclusive relacionados à composição da imagem) no que diz respeito à construção das questões ambientais brasileiras via mídia: de um lado, até meados dos anos 80, ele constata a onipresença de um repórter/narrador heroico a desbravar uma

\footnotetext{
${ }^{6}$ A primeira Conferência Internacional sobre o Meio Ambiente, organizada pela Organização das Nações Unidas, foi em Estocolmo, em 1972.

${ }^{7}$ Este Relatório ficou também conhecido como "Relatório Brundtland”, já que a Comissão era dirigida por Gro Harlen Brundtland, então ex-primeira ministra da Noruega.
} 
natureza espetacularmente grotesca; de outro lado, a partir dos anos 90, ele vê a emergência de uma complexificação das formas de representação da natureza e da ecologia, bem como de uma espécie de 'otimismo sustentável', que passam agora a permear decisivamente os meios de comunicação:

\begin{abstract}
No início dos anos 70 imperava, tanto no Brasil como no contexto mundial, um sentimento de pessimismo quanto à capacidade da civilização moderna em se adequar às demandas ecossistêmicas. Acreditava-se que a degradação ambiental seria irreversível e os limites do crescimento econômico haviam excedido os índices aceitáveis. Posições ambientalistas mais radicais e posturas tecnocráticas moderadas ocupavam a cena central, em que a cooperação e o diálogo tornavam-se escassos. [...]. A partir do final dos anos 80 , foi sendo estabelecida mundialmente uma ideia-força que teve condições de aglutinar todos os múltiplos anseios e perspectivas formulados em nível global: a noção de desenvolvimento sustentável. (ANDRADE, 2003, p. 161-162)
\end{abstract}

Ainda que o autor esteja remetendo a produções televisivas, importa destacar de sua análise uma marca importante, que passa a ser incorporada em tantos outros materiais audiovisuais que se valem do tema da sustentabilidade: "Forja-se, daí em diante, o otimismo da sustentabilidade, que irá se arraigar por diversos setores sociais, inclusive o espetacular ecológico" (ANDRADE, 2003, p. 162, grifo nosso).

Tomando como mote produtos audiovisuais cujo formato também se efetiva por uma espécie de 'apresentação do real' - tal como, portanto, os documentários -, o trabalho de Dutra (2009) analisa três programas de TV das Organizações Globo: Globo ecologia, Telecurso 2000 e Globo repórter. Para o autor, tais programas utilizariam "a velha estrutura narrativa das aventuras, da busca de lugares distantes e ermos para incluir, no texto, a recorrência enunciativa do tipo en estive lâ' (DUTRA, 2009, p. 32, grifo do autor). Além disso, de acordo com Dutra (2009, p. 32 , grifo do autor):

[...] o repórter ou apresentador de campo se insere como elemento estruturante do documentário, deixando de ser apenas um expositor de realidades distantes e exóticas para se tornar um figurante que testemunha realidades perigosas supostamente inalcançáveis para seus espectadores.

Neste sentido, e já articulando as questões trazidas por estas análises àquelas que aqui nos interessam, é importante considerar que Al Gore, em Uma verdade inconveniente, se mostra, ele mesmo, como elemento estruturante principal: tudo gira em torno dele, de sua vontade política, de sua 'visão' ecológica, de seus exemplos (familiares, morais).

Levando em consideração os filmes que tomamos como centrais em nossa análise - Uma verdade inconveniente (2006) e Lixo extraordinário (2010) -, podemos dizer, a partir dos estudos existentes voltados para as temáticas ambientais, que operamos com um tipo particular de cinema, qual seja, o 'cinema ambiental'. A este termo entende-se "filmes que explicitamente levantam questões ambientais ou veiculam ideologias ambientalistas" (CERQUEIRA; AGUIAR, 2013, p. 123). No assim chamado 'cinema ambiental', acreditamos, produz-se significações ou, 
mais do que isso, 'representações' dominantes sobre a natureza, geralmente calcadas em visões conservacionistas, preservacionistas, reformistas ou radicais (CERQUEIRA; AGUIAR, 2013). Ao entendermos 'representação' (HALL, 2006) menos como mero 'reflexo' dos eventos e das práticas que se erigem no social - e muito mais como complexos sistemas a partir dos quais os sentidos e as significações são construídos, produzidos e, a todo o tempo, disputados -, assumimos que essas formas dominantes de composição da imagem documental operam de modo decisivo para nossa compreensão acerca dos modos de olhar e atuar na cultura - daí merecerem ser analisadas e problematizadas.

No rol da análise das produções cinematográficas voltadas para a formação de uma 'consciência ecológica', Ieda Tucherman e Cecília Cavalcanti (TUCHERMAN; CAVALCANTI, 2008) nos trazem importantes considerações acerca da relação entre a produção de imagens contemporâneas (sobretudo aquelas ditas 'documentais') e a natureza. As autoras analisam o que denominam de "um novo gênero cinematográfico": o "documentário-catástrofe" (TUCHERMAN; CAVALCANTI, 2008, p. 37). Assim, tanto Uma verdade inconveniente, como Estamos mudando nosso planeta? (2005), de David Attenborough, são tomados pelas autoras como exemplos de uma ruptura fundamental na forma de o cinema-documentário fazer visível a natureza: não se trata mais de uma natureza selvagem, misteriosa, a que devemos desbravar; não mais a natureza eminentemente exuberante, diversa, "fotogênica" (TUCHERMAN; CAVALCANTI, 2008, p. 41), mas aquela que perde seu vigor, se enfraquece e dá sinais, visíveis e nítidos, de estar em atemorizante perigo. Em outras palavras, "os novos documentários mostram que este planeta está perdendo diversidade e beleza, deixando de ser aquele extraordinário mundo azul para ser uma imagem se decompondo em vários pontos" (TUCHERMAN; CAVALCANTI, 2008, p. 41). Trata-se, assim, de uma ruptura que traz em seu âmago uma natureza não mais bucólica e que, encantadoramente, nos rodeia, mas que, acima de tudo, nos invade e se volta contra nós. A ruptura sugerida é pautada pela composição de uma nova estética, que combina ficção-científica à tecnociência: "o tom empregado, a maneira de editar, os efeitos especiais, as trilhas sonoras e o público-alvo tornaram o modelo onde o índice catastrófico é mais que o explorado, o preferido" (TUCHERMAN; CAVALCANTI, 2008, p. 42).

O que nos parece estar em questão nesse conjunto diversificado de materiais midiáticos que esses autores colocam em análise, é a insistência em certas estratégias de convocação do espectador. Menos que sugerir práticas de questionamento e de debate, tais materiais investem, antes, no apelo ao choque, na lógica do 'soco do estômago' (KEHL, 2005), numa retórica da catástrofe em relação à qual a condição de acaso dos fenômenos é potencializada pela vulnerabilidade a que nós mesmos nos expomos, como sujeitos negligentes ao meio que habitamos (TUCHERMAN; CAVALCANTI, 2008). A avalanche de dados e a irrefutável crença nas imagens captadas (e mesmo naquelas que atuam, tecnologicamente, como projeção do futuro) erigem um novo marco na produção e apresentação midiática da natureza: somos, a um só tempo, vítimas e responsáveis pela degradação do planeta. 


\section{O cinema-documentário}

O cinema, já há décadas, vem colocando em relevo, sistematicamente, a relação entre homem e natureza. Ficções das mais diversas, como Terremoto, Inferno na torre inauguram, na década de 70, uma série de produções americanas voltadas para o grande público e cuja forma de abordagem, de algum modo, se sustenta e cria uma 'estética do espanto' - tanto no que se refere às imagens, quanto ao conteúdo que evocam (TUCHERMAN; CAVALCANTI, 2008). Nos últimos tempos, proliferam as produções voltadas para a narrativa-espetáculo, na qual a natureza que mata, que destrói e que aterroriza assume o protagonismo: Independence Day, Armagedom, Mar em fúria, Vulcano, $O$ dia depois do amanhã, Impacto profundo, Twister (TUCHERMAN; CAVALCANTI, 2008).

Uma primeira e rápida leitura destes materiais poderia pressupor que tais filmes dizem respeito a meras ficções e que, nesta condição, pouca relação possuiriam com aqueles aqui analisados. No entanto, merece ser dito que partimos de um ponto específico ao tomarmos o gênero documentário como material de análise, qual seja, aquele que aposta que, ao fim e ao cabo, "todos os grandes filmes tendem ao documentário, como todos os documentários tendem à ficção. [...] Quem opta por um necessariamente encontra o outro no final do caminho" (GODARD, 1985, p. 144, tradução nossa) - o que não significa afirmar, imediatamente, que eles sejam iguais. Dizendo de outro modo, cremos que o gênero documentário talvez seja o tipo de produção fílmica que coloca em jogo de forma mais pontual a dualidade entre 'real' e 'ficção'.

O 'cinema do real' encontra-se predominantemente assimilado a uma ideia geral de produção de imagens mais 'puras', que, nesta condição, atuariam como uma espécie de reflexo fiel da natureza (a natureza, digamos, 'tal como ela é'). Ainda assim, as imagens criadas na rede narrativa do documentário funcionariam, também supostamente, como testemunhas de uma realidade que, a princípio, lhes seria preexistente. Como duvidar de depoimentos tão genuínos, tão 'consistentes' como aqueles expressos por Al Gore e Vik Muniz (por mais diferenças que guardem entre si)? Como duvidar daqueles que se colocam como especialistas do tema (e que estão também cercados por dados tabelas, gráficos, projeções) ou daqueles que vivem, 'na própria carne', a condição de responsabilidade ambiental? Menos do que considerar tais perguntas de modo afirmativo, ao fazê-las nosso intuito é, justamente, questionar os pressupostos que elas carregam.

Acreditamos que os documentários operam com as categorias de 'verdade' e de 'real'; neste caso, no entanto, não se trataria de uma 'verdade' e de um 'real' que estariam presos direta e isoladamente 'na' imagem, mas, antes, 'na relação' que estabelecemos com ela (o que significa apostar naquilo a que somos por ela convocados) e que, a nossos olhos, como resultado de uma operação de linguagem (fílmica) tão complexa como singular, se faz 'verdadeira' e 'fruto da realidade'. Assim, nossa intenção neste texto é fazer jus àquilo que tão claramente nos escreve Xavier (1998, p. 379), ao dizer que "toda leitura de imagem é produção de um ponto de vista: o do sujeito observador, não o da 'objetividade' da imagem”. Isso nos convoca a outro processo de análise, qual seja, aquele que se preocupa em caracterizar os 'regimes de credibilidade' (MARCELLO, 2010) estabelecidos por estes materiais, uma vez que entendemos que o 'real' da imagem está ligado às formas de sua construção e, sobretudo, às formas por meio das quais somos convocados a dar sentido e valor a ela. 
É preciso destacar que não estamos afirmando que Al Gore ou Vik Muniz (ou seus diretores) tenham 'inventado' algo até então inédito. No lugar de situar tais sujeitos no espaço de uma origem discursiva, nosso interesse está em caracterizar o modo como, nos filmes, combinam-se, com fins específicos, elementos próprios da narrativa documentária, tais como: “presença de locução (voz over) $)^{8}$, presença de entrevistas e depoimentos, utilização de imagens de arquivos, rara utilização de atores profissionais [...], intensidade particular da dimensão da tomada", bem como "procedimentos como câmera na mão, imagem tremida, improvisação, utilização de roteiros abertos, ênfase na indeterminação da tomada” (RAMOS, 2008, p. 25).

Além disso, acreditar que o documentário, como gênero filmográfico, opera a partir de 'regimes de credibilidade' (MARCELLO, 2010), que ele se vale de estratégias particulares de convencimento ou mesmo que faz uso de recursos específicos para a composição de 'verdades', tal como sugere a autora, nada têm a ver com a afirmação direta e linear de que eles 'manipulam', que eles 'mentem' ou mesmo que 'enganam'. Trata-se, antes disso, de uma aposta teórica importante, que, com efeito, implica em mostrar, isto sim, que concepções e argumentos, por mais que organizados a partir de imagens 'reais', por compostos por dados, gráficos e números de espessura realista, são sempre composições em nada neutras; que existe, portanto, um conjunto de relações tramadas em torno da construção de algo que se situa na ideia de que, neles, "a noção de verdade, muitas vezes, se aproxima de algo que definimos como interpretação" (RAMOS, 2008, p. 32, grifos do autor). Neste sentido, não cabe mostrar, em contraposição aos argumentos dos filmes escolhidos, se algo ali é, efetivamente ou não, 'verdadeiro' - importa-nos caracterizar as múltiplas estratégias elaboradas para que algo 'seja tido como tal'.

\section{Uma verdade inconveniente: ou de como tínhamos esquecido de como era o mundo}

Em Uma verdade inconveniente, há um eixo central, condutor de grande parte (ou mesmo da totalidade) das discussões: tudo se dá em torno do estabelecimento do aquecimento global como um fato irrefutável. Dizendo de outro modo, a natureza e os seres humanos correm o risco de desaparecer em virtude das elevadas emissões de carbono que o desenvolvimento humano vem provocando, em especial, desde a Revolução Industrial. Essa verdade científica supostamente inarredável (e, por isso, dita 'inconveniente') vai sendo construída ao longo de toda a narrativa de muitas e diferentes formas, por meio daquilo que Marcello (2010) chama de 'regimes de credibilidade', como referido.

Neste sentido, pode-se dizer que em Uma verdade inconveniente a força da 'verdade verdadeira' - ou seja, os 'regimes de credibilidade' - acerca do ambiente e da necessidade de um desenvolvimento humano sustentável são produzidos, pelo menos, de duas formas: primeiro, por uma espécie de 'antes e depois' e, segundo, complementariamente, por uma sensação perturbadora de 'causa e consequência'. O documentário inicia evocando imagens e sentimentos bucólicos: galhos e folhas muito verdes em primeiro plano, em close; em segundo plano, um córrego calmo, de águas quase paradas, sob luz branda do sol. A imagem de tranquilidade é

\footnotetext{
${ }^{8}$ Trata-se de uma voz cujo interlocutor não vemos; ela pauta as cenas, estrutura a ação e é direcionada diretamente ao espectador.
} 
fortalecida por delicados traços de sombra das folhas, que parecem sugerir apenas uma leve e confortante brisa. Em meio ao cenário, a voz de Al Gore surge como a força condutora da narrativa (em over): "Vemos esse rio fluindo suavemente. Percebemos as folhas sussurrando com a brisa. Ouvimos os pássaros. Ouvimos os sapos. Ouvimos uma vaca mugindo. Sentimos a grama, a lama caindo na margem do rio. Está tudo quieto, tranquilo. E, repentinamente, uma apaziguadora voz diz: "tinha me esquecido de como era". Ali mesmo, somos surpreendidos. Uma transição abrupta das imagens logo que a enunciação "tinha me esquecido de como era" é feita - e a qual é seguida de um longo suspiro; vê-se, então, não mais as imagens claras, calmas e brilhantes de um segundo atrás, mas aquela do planeta Terra na tela de um notebook. A ruptura emerge em forma de uma saudade dolorida: transportados de um lugar calmo e eminentemente verde para um palco repleto de pessoas, somos lançados diretamente para a palestra high-tech de $\mathrm{Al}$ Gore, e a frase, assim, passa a adquirir outro sentido: "tinha me esquecido de como era bonita a Terra". Junto a isso, temos uma edição de imagens de diferentes palestras de Al Gore (inclusive em outras partes do mundo, como indica uma faixa escrita em japonês e posicionada em um dos auditórios mostrados); imagens em meio a um público ávido por tirar fotos dele e, claro, junto a ele - e sugerindo ali, portanto, como se já não estivesse claro, que se trata não de 'qualquer' narrador, de 'qualquer' apresentador: "Eu sou Al Gore. Já fui o 'futuro presidente' dos Estados Unidos”.

Há, de maneira mais evidente, um apelo já inicial pela preservação da beleza da Terra (dos continentes, dos ambientes naturais), mas, à medida que o filme prossegue, o apelo acaba se compondo de outra forma, no limite, comovente: trata-se, então, da preservação de nossa 'casa', a Terra, pequena em comparação com o restante do cosmos e bastante singular (e a enunciação agora já parece nos dizer: "tinha me esquecido de como era pequena e frágil a Terra”).

Ao longo do documentário, a frase "tinha me esquecido de como era" adquire, ainda, novas conotações. Em determinado momento, entende-se que o cenário calmo e tranquilo que o ex-vice-presidente diz ter 'esquecido' lhe é, na verdade, bastante familiar: aquilo de que ele 'se esquecera' era uma parte da propriedade de seu pai, plantador de tabaco e pecuarista até meados dos anos 1960. Al Gore 'lembra-se', por meio de um vídeo caseiro, de quando ele ainda era um garoto; por meio daquele vídeo tão singelo, as imagens desbotadas e trêmulas de sua infância feliz e cheia de liberdades junto à natureza do campo, passam a servir para questionar as atividades de seu próprio pai (principalmente quando ele menciona que uma de suas irmãs morreu de câncer de pulmão e que seu pai parou de plantar tabaco depois disso). Assim, ao articular situações aparentemente tão distintas e das quais, insistentemente, diz ter-se 'esquecido de como era' (a beleza da propriedade de seu pai antes das plantações de tabaco; a imagem de sua irmã antes da morte em função do fumo; a imagem de seu filho antes de um acidente de carro neste caso, especialmente, composta pela alternância da narrativa a imagens fixas [fotografias], em preto e branco e levemente granuladas, de um hospital vazio, em diferentes perspectivas (quartos, salas de espera, sala cirúrgica) com aquelas do pequeno menino, sorridente, como em qualquer acervo familiar; o azul da Terra na primeira imagem tirada do espaço), Al Gore projeta, a um só tempo, comoção e alerta. No jogo da linguagem cinematográfica, trata-se, afinal, da possibilidade da perda de algo importante e, supostamente, em um estado anterior de pureza e virtude (a natureza, a irmã, o filho, a memória); trata-se, também, da construção de um conjunto de tragédias, catástrofes e perdas (individuais e coletivas, privadas e públicas) "que atinge no coração visual nosso afeto por este planeta e esta vida" (TUCHERMAN; CAVALCANTI, 2008) - e voz visivelmente pesarosa, pausada e baixa de Al Gore reforça de maneira decisiva estes aspectos. 
O conjunto de tragédias, catástrofes e perdas fica ainda mais evidente a cada 'amigo famoso' que Al Gore invoca (cientistas mortos, perseguidos em vida devido aos resultados de seus trabalhos), tais como os físicos Carl Sagan e Roger Revelle (que trabalhou na NASA e desenvolveu os primeiros estudos sobre os efeitos nocivos das emissões de carbono para o aquecimento global). O que se observa é que, a cada vez que ele utiliza determinados recursos (tão múltiplos como, distintamente, 'críveis' a seus argumentos, tais como gráficos, tabelas, fotografias antigas, simulações de computador, recortes de jornais e revistas, desenhos animados assinados por Matt Groening, criador dos Simpsons), ele o faz para enfatizar a destruição progressiva do planeta. O percurso sinuoso e apenas aparentemente pouco concatenado de sua fala compõe sentidos bastante precisos. Este é, aliás, um recurso narrativo recorrente do filme. Al Gore se vale desde uma grua para deixar evidentes as medidas assustadoras do gráfico das emissões de gás carbônico na atmosfera ao uso das piadas e do deboche de si mesmo. Nessa composição tão heterogênea, somos também apresentados às 'verdadeiras imagens do Apocalipse' (muitas delas, inclusive, extraídas de jornais e de telejornais, ou seja, 'ao alcance de todos'): os milhares de mortos em função do calor excessivo de 2005, as cenas de destruição causadas pelo Furacão Katrina em Nova Orleans, os violentos tornados, tufões, alagamentos e secas - eventos mostrados ora como consequências terríveis dos atos (igualmente terríveis) da humanidade, ora como uma mensagem dos deuses (de que algo precisa ser feito com urgência), ora como uma simples (e inconveniente) verdade. Em suma, pelo entrecortado universo de informações e imagens das mais diferentes fontes (científicas, midiáticas, de arquivo pessoal), sustentam, de diferentes perspectivas, que, de fato, a natureza 'enlouqueceu'.

$\mathrm{Na}$ tessitura imagético-narrativa, a credibilidade do documentário e daquilo que ele sustenta são acentuados, justamente, pela sensação de cotidiano e de familiaridade produzidas pelas páginas de jornal e cenas de noticiários que entremeiam a narrativa - essas produtivas 'tecnologias visuais da verdade' (DUSSEL, 2009), por meio das quais a imagem nos é dada numa relação imediata de confirmação, de conformação e nas quais o ato de ver se torna sinônimo de crer ('ver para crer', como refere a máxima popular). Assim, não parece se tratar de algo 'distante' ou, ainda, de algo que está por vir: o Apocalipse é agora, é NOW, com a morte e a extinção de espécies, a invasão de plantas e insetos considerados 'exóticos', com o aumento do número de doenças infecciosas e a emergência de vírus terríveis, a morte dos recifes de corais em função da poluição das águas continentais, o aumento das migrações humanas (e, também, do número de desabrigados) em função de guerras, secas, fome, enchentes etc.

De fato, pode-se dizer que a retórica do otimismo sustentável marca os dois documentários ora analisados. No caso de Uma verdade inconveniente observa-se que a música de encerramento 9 é entremeada por mensagens imperativas e, mais do que isso, indicativas de ações, individuais (ainda que pareçam remeter, em alguns momentos, à coletividade), que podem (e vão) 'dar certo': você pode trocar as lâmpadas da sua casa por versões mais econômicas; se puder, compre um carro bibrido; sempre que puder, ande ou use a bicicleta; onde puder, use transporte público; passe a usar fontes de energia renovável; veja se sua companbia elétrica oferece 'energia verde' - se não oferece, pergunte por quế; eleja lideres que prometam resolver esta crise. Se não ouvirem, recorra ao Congresso; plante árvores, muitas árvores;

\footnotetext{
${ }^{9}$ I need to wake up (que pode ser traduzido livremente por Preciso acordar), de Melissa Etheridge.
} 
se você acredita em oração, reže para as pessoas encontrarem forças para mudar, e assim por diante. Ora, o que está em jogo aqui é o reforço de um dos elementos que, em grande medida, tem marcado o tempo contemporâneo: a privatização de questões públicas. Mais precisamente, como afirma Bauman (2001, p. 43), cada vez mais, "riscos e contradições continuam a ser socialmente produzidos; são apenas o dever e a necessidade de enfrentá-los que estão sendo individualizados". A problemática lançada por Bauman emerge de uma reconfiguração das esferas que remetem à coletividade (e, com efeito, ao sentido mesmo de cidadania) e aquelas de individualidade, uma vez que, cada vez mais, “o 'público' é colonizado pelo 'privado”' (BAUMAN, 2001, p. 46).

Com isso, enfatizamos um importante recurso de interpelação em ato no filme, qual seja, aquele descrito por Tucherman e Cavalcanti (2008, p. 38) como "mediação pendular", e que, neste caso, diz respeito à forma como os materiais mais diversos "oferecem a crise, aterrorizam e oferecem uma hipótese de solução” (TUCHERMAN; CAVALCANTI, 2008, p. 38). Nos 'regimes de credibilidade' da imagem estabelecidos por Uma verdade inconveniente, a tessitura desses/entre esses dois polos é feita via instauração de uma conexão de difícil refutação, sobretudo pela relação inversamente proporcional entre a recrudescente gravidade dos problemas face à ampla (mas aparentemente tão simples) possibilidade de sua solução (ou, pelo menos, de seu atenuamento), recorrendo-se, para tanto, à máxima tão edificante quanto ingênua do 'cada um fazer sua parte'.

Ainda assim, dando seguimento a uma análise que não separa conteúdo e forma, o chamado 'ponto de vista' é crucial para que se estabeleçam parâmetros para a discussão do filme. No cinema (mas não só), segundo Jullier e Marie (2009, p. 22), “o ponto de vista é apresentado pela localização da câmera. É o ponto de observação da cena, aquele de onde parte o olhar”, não sendo, de modo algum, neutro, acidental ou aleatório, mas, antes, pensado, articulado, orquestrado em termos de narrativa e de fruição. Como isso se dá no filme de Al Gore? Um dos exemplos desta estratégia pode ser visto em uma das sequências mais marcantes: ali, logo após termos sido apresentados ao rio da infância de Al Gore, como testemunhas de um tempo ideal (e idealizado) que, talvez, não volte mais, somos violentamente reposicionados: agora, 'olhamos' para os ombros e para a parte de trás da cabeça de Al Gore. A cena é cinzenta; ele, ao contrário, parece caminhar em direção a uma luz. A câmera - ou, quem sabe, nós, espectadores - somos situados atrás dele, como se o seguíssemos em direção a algo desconhecido. Em determinado ponto da narrativa, somos levados a crer que estamos, de fato, no lugar dele, subindo ao palco - para uma campanha, para uma palestra? De qualquer forma, para um lugar de destaque e de ação. Em seguida, quando ouvimos a voz de um apresentador dizendo "Senhoras e senhores, o Senhor Al Gore" e o barulho de uma plateia saudando este homem que está de costas para nós, a posição se torna absolutamente 'inconveniente' e insuportável: estamos imaginariamente (ou melhor, imageticamente) tentando olhar por cima dos seus ombros; estamos, talvez, 'pesando nos ombros' de apenas um homem; estamos atrás dele, como sombras. Logo em seguida, no entanto, a sensação de inconveniência se desfaz, sendo substituída por uma sensação positiva de pertencimento à massa de pessoas que ouve o que $\mathrm{Al}$ Gore tem a dizer sobre o aquecimento global (ou que, depois, o cerca para cumprimentar, agradecer, sorrir, olhar, tocar, conversar, tirar fotos). 'Nós' aqui, no entanto, parece funcionar como um sentido de ilusória coletividade, já que 'nós', aqui, não deixa de ser, apenas e tão-somente, "um agregado de 'eus"” (BAUMAN, 2001, p. 78). 


\section{Lixo extraordinário: ou das extraordinárias possibilidades}

De Wall-E a Ilha das Flores, de Estamira a Boca do lixo: o cinema tem sido um campo fértil a por em cena, de distintas maneiras, a problemática do lixo. Em sua discussão sobre os aspectos que caracterizam o tempo contemporâneo, Bauman (2005) nos mostra que o lixo se faz hoje 'produto' e fértil 'metáfora' para a compreensão de como nos situamos e nos inscrevemos na cultura. Como produto, ele e seu acúmulo são resultados diretos de uma sociedade definida pelo consumo. Ainda que saibamos que, como nos diz Bauman (2001), o consumo sempre existiu, a diferença se situa no fato de que, diferente do século XIX, em que se produziam sujeitos e relações marcados pela 'produção' (afinal, a escola, as fábricas foram, neste período, caracterizadas por isso, para a organização de uma sociedade de produção, ocupadas, pois, com um indivíduo na qualidade de 'produtor potencial'), hoje vemos que a marca decisiva de práticas, instituições e sujeitos opera a partir do pressuposto de que, desde cedo, devemos nos ocupar em consumir (um rápido panorama pela publicidade, pelas redes sociais nos mostram o quanto, já desde muito pequenas, as próprias crianças são cotidianamente 'ensinadas' a serem consumidoras). Menos do que uma crítica voltada aos aspectos morais desta constatação - e que, nesta condição, se resumiria a rechaçar o consumo e a sociedade consumista -, importa-nos mostrar seus efeitos. Em outras palavras, interessa-nos mostrar, o que, 'a partir' dessa alteração, podemos pensar e problematizar, tendo em vista nosso objeto em análise.

Neste momento, estou em um ponto da minha carreira em que quero me distanciar do
dominio das belas artes - pois acho que é um espaço muito exclusivo e restritivo. O
que realmente quero fazer é ser capaz de mudar a vida de um grupo de pessoas com o
mesmo material que elas lidam todos os dias. Não um material qualquer. A ideia para
a minha próxima série é trabalhar com o lixo. [Vik Muniz, em Lixo extraordinário].

É desse desejo, expresso pelo artista plástico brasileiro Vik Muniz, que parte o documentário Lixo extraordinário, produzido em 2010, mas filmado durante dois anos (de agosto de 2007 a maio de 2009). O filme narra a convivência do artista, radicado em Nova York, com os catadores de lixo que trabalham no maior aterro do mundo: o aterro sanitário Jardim Gramacho, no Rio de Janeiro. O filme, aliás, é repleto de panorâmicas que, diante do lixo, nos colocam em posição de repulsa e fascínio: tal como os cidadãos da cidade imaginária de Leônia, de Borges, vemos Gramacho como réplica de nós mesmos: vorazes pela novidade, pela possibilidade, insistente de sempre "desfrutar de coisas novas, diferentes", somos convocados a olhar "cheios de preocupação, medo e tremor" para aquelas montanhas e, sobretudo, a "se horrorizar com essa visão" (BAUMAN, 2005, p. 8). Mais uma vez, tal como no filme anterior, lá é aqui; eles somos nós.

Em meio ao lixo, o artista (e seu assessor Fábio), se instalam e passam, por um período de dois anos, a desenvolver um trabalho que consiste em tirar fotografias dos catadores. Em seguida, algumas destas fotografias (minuciosamente selecionadas) são projetadas do alto de um imenso galpão/ateliê para o chão - galpão que Vik Muniz aluga próximo ao aterro, de forma a poder realizar sua proposta. Projetadas no chão, as imagens fotográficas tornam-se telas de grandes dimensões, as quais os próprios catadores, sob direção do artista, 'preenchem' com lixo: olhos compostos de garrafas PET, cabelos feitos de tampinhas de garrafa, sombras desenhadas com pneus. Eis aí realizada mais uma das séries de trabalho de Vik Muniz e que 
mantém sua marca: incorporar às obras a vida dos objetos do cotidiano. Se em trabalhos anteriores o artista se utilizava de elementos como areia, açúcar, pasta de amendoim e chocolate (alguns deles também implicados em questões sociais), aqui é o lixo que se faz 'extraordinário'.

No conjunto das imagens, uma das estratégias utilizadas é aquela de fazer visível a dor e o descaso de vidas - as quais parecem ganhar alguma dignidade quando alçadas pela arte (seja pela arte, em si mesma, tal como proposta pelo artista, seja também por aquela que, pelas imagens do documentário, passamos a acompanhar). Em uma das muitas conversas em que analisam os materiais coletados (especialmente filmagens de Gramacho), capturadas por imagens que apenas parecem apresentar conversas triviais e despretensiosas, Vik Muniz e seu assessor concluem: "Até agora, [o fator humano] é a melhor parte do que encontramos lá. O fator humano lá é belo". Não se trata mais, então, somente de arte, mas de uma arte-política, que retém do lixo a beleza e dos catadores a condição, também deles, de serem 'extraordinários'.

Lixo e pessoas se equivalem; em grande volume, parecem desaparecer. Em meio às tomadas aéreas, às imagens do trabalho dos catadores, montanhas de lixo misturam-se aos closes de mãos que catam, a urubus que, com elas, disputam espaço. O barulho ensurdecedor dos caminhões se torna visível por tomadas de câmera que os destaca na ampla superfície do aterro. Ali, sem cessar, eles chegam e despejam centenas de quilos de dejetos; ali vemos a correria entre os catadores para chegar até eles o mais rapidamente (e, portanto, colher daqueles restos despejados o que for mais valioso). Convencemo-nos da grandeza e da importância tanto daquelas vidas, como daquela forma de arte que ali se instaura com a presença de Vik Muniz e seu projeto.

Não por acaso, lixo e ser humano são tomados como sinônimos - no caso do documentário, isto se faz justamente para mostrar a importância da superação desta relação. Aos olhos da discussão de Bauman (2005), tratar-se-ia de 'vidas desperdiçadas' - não no sentido de que são perdidas ou não aproveitadas, mas naquele que as inscreve como tal. Para o autor, a modernidade se instituiu sob a ideia de que o funcionamento de uma 'boa sociedade' estaria radicado na disponibilização de emprego a todos (como dito acima, algo que, portanto, se mostra em sintonia com uma sociedade voltada para a 'produção'). Hoje, no entanto, nos encontramos prioritariamente marcados por outra condição: aquela sob a qual a capacidade de consumir é medida de pauta para a noção de desenvolvimento e eficácia do social. Na qualidade de 'consumidores falhos', esses sujeitos se apresentam como 'refugo humano' (BAUMAN, 2005, p. 42): eles não incitam o consumo (ou dele são privados); são indivíduos que se tornam visibilizados justamente pelo perigo que representam, supostamente, para esse modelo de sociedade ('perigos' a que damos o nome de 'vulnerabilidade social', 'marginalização', 'risco de violência', 'de drogadição', etc.); “o refugo é o segredo sombrio e vergonhoso de toda a produção” (BAUMAN, 2005, p. 38).

A importância dos sujeitos é pautada pelo amplo conjunto de depoimentos que o documentário reúne. Num tom quase didático, somos apresentados à grandeza de um trabalho anônimo e silencioso pelas mais diferentes vozes. Primeiramente, pela fala daqueles que gerem as associações de catadores da região. De seu escritório, ao lado de Vik e Fábio, o ex-catador Tião explica: "Os catadores tiram 200 toneladas de lixo por dia. Isso é representativo de uma cidade de 400.000 habitantes. Ai você vê a importância do catador hoje, pra Gramacho, é muita, porque tá aumentando a vida útil [dos materiais]". A importância do trabalho é dada, igualmente, pela fala de um dos próprios catadores: Valter dos Santos, entrevistado ali mesmo, no aterro: com chapéu e lenço usados para proteger-se do sol escaldante, a imagem do catador paulatinamente se fecha até que, aos poucos, temos em close seu rosto, visivelmente envelhecido e cansado. 
Sou catador aqui há 26 anos. Tenho orgulho de ser catador. Sou vice-presidente da Associação de Catadores do Aterro Metropolitano do Jardim Gramacho. Sou representante, aqui, dentro do aterro, de 2.500 catadores - e isso eu carrego com orgulho. Digamos que cada casa gere 1 quilo de lixo. E que 1 quilo de lixo gere 500 gramas de material reciclável. Em 1.000 residências, isso se transforma em 500 quilos de material reciclável. Já é menos que vem pros rios, lagoas, entupindo as valas, o esgoto, ou até mesmo vindo pro aterro. [pausa] Fazemos um grande mal para a natureza e o meio ambiente. Tento convencer as pessoas do quê? O que é um material reciclável e quale e material orgânico. O que ele deve faz̧er? Às vezes eles dizem assim: 'Mas uma latinha...' Uma latinha tem muita importância. Por quê? Porque 99 não é 100 - e essa uma vai completar.

Com esses depoimentos, vemos se compor um potente 'regime de credibilidade', qual seja, aquele que sugere que a grandeza do trabalho do artista se faz visível proporcionalmente à condição abjeta dos trabalhadores, bem como, especialmente, àquela terrificante do aterro de Gramacho. Questionado pelo assessor Fábio se Vik acharia difícil trabalhar em Gramacho (tendo em vista os perigos do lixo e aqueles implicados com a proximidade do aterro a áreas de tráfico), o artista responde (mais uma vez, uma conversa trivial, como que realizada naquele que seria apenas mais um dia de trabalho, no escritório de Vik, junto a computadores e livros): "Não, pois acho que seria mais difícil pensar que não podemos mudar a vidas dessas pessoas. Creio que podemos. Vale a pena tentar.' Desta forma, vê-se uma perspectiva de abordagem do tema da sustentabilidade, radicada na crença de que, em primeiro lugar, estão as pessoas e que é o estatuto que recebem culturalmente que merece ser modificado. Diz Vik: "A gente tá tentando criar um retrato do catador porque o catador é uma pessoa. Como o lixo que tá aqui, o catador é uma pessoa que ninguém conhece".

Como no grande aterro, as pessoas também são objeto de seleção: vidas desafortunadas, evidenciam sua riqueza, sua capacidade de mostrarem-se belas e, acima de tudo, 'recicláveis': o catador que procura livros e que conhece Maquiavel, Nietzsche, que fala sobre a história das guerras, da história da arte; a catadora que faz, ela mesma, 'com sol ou chuva', comida para todos os colegas; a mãe adolescente que sustenta a casa de duas peças na qual vivem mais de oito pessoas; a mulher apaixonada por um caminhoneiro casado, que, emotiva, narra passagens dramáticas de sua vida para a câmera. Todos eles são personagens do filme e são eles que, de algum modo, conduzem a narrativa ao ápice: o momento em que a primeira tela que produzem é vendida pelo equivalente a R \$ 100.000 em uma casa de leilão, em Londres. Depois disso, como afirma o presidente da Associação, "Tudo parece faz̧er sentido". Tal como nos diz Bauman (2005, p. 76-77),

Em seus sonhos noturnos podem moldar-se à semelhança dos consumidores, mas é a sobrevivência física, e não a orgia consumista, que lhes ocupa os dias. Está montado o palco para o encontro dos dejetos humanos com as sobras das orgias consumistas - de fato, parecem ter sido feitos uns para os outros...

No entanto, uma tensão parece atravessar o documentário - e é exposta, também desde o início, pelo artista: "Trata-se de uma experiência de como a arte pode mudar as pessoas, mas também se ela realmente pode mudar. Será que isso pode ser feito? E qual seria o seu efeito?". Sustentabilidade e arte se unem aqui numa relação instável, incerta: vale a pena? Vale a pena 'iludir' os catadores como pergunta a esposa de Vik, também personagem da narrativa? É ele quem nos responde, numa imagem tensa, na qual acompanhamos o que seria a mera discussão de um casal): "Minha experiência com a mistura da arte com projetos sociais é a principal coisa, tirar as pessoas, nem que seja por 
alguns minutos, do lugar onde elas estão. E mostrar-lhes um outro mundo, um outro lugar. Isso muda tudo". Minutos depois, a edição das imagens parece apenas confirmar a resposta do artista: na fala, por certo comovente, da catadora que, ao entrar em contato como o ateliê e lá trabalhar durante um período, afirma nunca mais querer voltar para Gramacho: "Ah, mudou muita coisa. Eu não tô me vendo mais naquele lixo! Tô não! [Pausa. Isis, a catadora, se emociona] Eu não quero ir pro lixo, não".

O documentário aqui analisado, como pode ser visto, não opera com as mesmas estratégias de Uma verdade inconveniente. Não se trata de um documentário-catástrofe, cuja natureza se volta contra o homem. Contudo, merece ser dito que outras estratégias são postas em jogo para um outro tipo de apelo na relação do humano com a natureza e seus desejos. Em Lixo extraordinário vemos em cena uma 'retórica do otimismo sustentável', operada pela maneira positiva e oportuna com a qual aqueles que se ocupam das toneladas intermináveis de resíduos produzidos pela sociedade são tornados visíveis. A natureza parece apagada, mas é seu silêncio que fala de algo, talvez, mais perigoso: os seres humanos são aqueles responsáveis pelo acúmulo de um material que a natureza, em si mesma, não produz. O lixo produzido e nos dado a ver via as imagens sem fim das montanhas do aterro de Gramacho é aquele que precisa ser reciclado. Da mesma forma, os personagens são vítimas de um sistema impiedoso de produção-descarte das grandes cidades. No entanto, tal retórica aposta nas vias alternativas, que supõem que, alçados pela arte, eles possam ganhar o papel de heróis anônimos.

\section{Algumas conclusões}

Ao afirmar tantas vezes sobre o caráter construído dos sentidos, das 'verdades', indicamos que, de igual maneira, aquilo que sistematizamos em termos analíticos também pode (e deve) ser tomado em sua provisoriedade. Ou seja, compor este texto, descrever os materiais significou operar com 'uma' forma particular de entendê-los, que, longe de pretender-se ser última e irrefutável, é resultado de olhares singulares, possibilitados graças ao arcabouço teórico do qual nos valemos. Certamente, sobre os 'mesmos' materiais, outras e muitas leituras são e foram elaboradas (MARQUES; SENNA, 2013; MACHADO; MORAES, 2014).

Traçando um paralelo entre tais produções fílmicas, podemos observar maneiras muito diferentes de captura do espectador e de instauração de 'regimes de credibilidade': por um lado, o documentário protagonizado por Al Gore se constrói a partir de uma 'estética do espanto', em que mais do que inserir a crítica, opera pelo choque e pelo terror de que a Terra vê seu fim próximo. Por outro, em Lixo extraordinário, ao mostrar o cotidiano de catadores de material reciclável em um dos maiores aterros sanitários do mundo (Gramacho, no Rio de Janeiro), dá-se visibilidade a outras formas de vulnerabilidade (e, consequentemente, de sustentabilidade), por meio da arte. Isso nos permite sistematizar duas lógicas - em seu limite, paradoxais - a partir das quais os filmes se organizam e pelas quais podemos entender que se processa um tipo de 'pedagogia da imagem': (1) a de que a degradação ambiental faz-se associada à degradação humana (lógica construída a partir de uma 'gramática do catastrofismo'); (2) a da 'retórica do otimismo sustentável' (no caso, expressa pela exibição ad nauseam de experiências e iniciativas ecologicamente sustentáveis) (ANDRADE, 2003).

Em comum, como visto, tais lógicas são sustentadas por elementos definidores hoje da cultura, seja em seu viés individualizador (em que o sujeito é posicionado como 'capaz' e, 
ainda, é empoderado quanto às possíveis soluções ou saídas dos impasses que nos afligem), seja pelo viés de uma sociedade orientada e justificada pelo consumo. Em sua relação com a sustentabilidade, o que parece estar em jogo é, simultaneamente,

[...] a apropriação material e simbólica da natureza, tanto por discursos justificadores da sua exploração, quanto por embates discursivos sobre os limites da sua espoliação, que vêm se intensificando no contexto da utopia do 'desenvolvimento sustentável'. (CERQUEIRA; AGUIAR, 2013, p. 120)

\section{Agradecimentos}

Ao Conselho Nacional de Desenvolvimento Científico e Tecnológico (CNPq) pela bolsa de produtividade em pesquisa concedida à primeira autora deste trabalho.

\section{Referências}

ANDRADE, T. Ecológicas manhãs de sábado: o espetáculo da natureza na televisão brasileira. São Paulo: Annablume: FAPESP, 2003.

BAUMAN, Z. Modernidade líquida. Rio de Janeiro: Jorge Zahar, 2001.

. Vidas desperdiçadas. Rio de Janeiro: Jorge Zahar, 2005.

CERQUEIRA, J. F.; AGUIAR, S. A representação da natureza no longa-metragem Rio. In:

GUIMARÃES, L.; GUIDO, L. E. (Org.). Cinema, educação e ambiente. Uberlândia: UFU, 2013. p. 119-136.

DUSSEL, I. Escuela y cultura de la imagen: los nuevos desafios. Nómadas, Bogotá, n. 30, p. 180-195, 2009. Disponível em: <http://www.redalyc.org/pdf/1051/105112060014.pdf>. Acesso em: 11 out. 2016.

DUTRA, M. A natureza da mídia: os discursos da TV sobre a Amazônia, a biodiversidade, os povos da floresta. São Paulo: Annablume, 2009.

ESTAMOS mudando nosso planeta? Londres: BBC, 2005. (Série televisiva).

EX-JORNALISTA chinesa revoluciona internet com documentário sobre poluição. São Paulo: [s.n.], 2015. Disponível em: <http://noticias.terra.com.br/ciencia/sustentabilidade/ex-jornalista-chinesarevoluciona-internet-com-documentario-sobre-poluicao,2f6df02473edb410VgnCLD200000b2bf46d0 RCRD.html>. Acesso em: 11 out. 2016. 
GODARD, J-L. Jean-Luc Godard par Jean-Luc Godard. Paris: Etoile, 1985.

GONZALEZ, A. Entre a verdade de Al Gore e a dos céticos, perde quem sofre o aquecimento. Portal G1, 14 jan. 2015. Disponível em: <http://g1.globo.com/natureza/blog/nova-etica-social/ post/entre-verdade-de-al-gore-e-dos-ceticos-perde-quem-sofre-o-aquecimento.html>. Acesso em: 11 out. 2016.

GUIMARÃES, L.; GUIDO, L. Encontros entre o cinema, a educação e o ambiente. In: (Org.). Cinema, educação e ambiente. Uberlândia: UFU, 2013. p. 7-12.

HALL, S. A identidade cultural na pós-modernidade. Rio de Janeiro: DP\&A, 2006.

JULLIER, L.; MARIE, M. Lendo as imagens do cinema. São Paulo: SENAC, 2009.

KEHL, M. R. Um épico de vidas infames. Folha de S. Paulo, São Paulo, 13 nov. 2005. Caderno Mais! Disponível em: < http://www1.folha.uol.com.br/fsp/mais/fs1311200504.htm>. Acesso em: 5 out. 2015.

LIXO extraordinário. Direção: Lucy Walker, João Jardim, Karen Harley. Produção: Angus Aynsley, Hank Levine. Intérprete: Vik Muniz. [S.1.]: Almega Projects: O2 Filmes, 2010. 1 DVD, son., color.

MACHADO, M.; MORAES, P. Lixo extraordinário: a arte de criar, reciclar e representar. Cadernos de Pesquisa do CDHIS, Uberlândia, v. 27, n. 1, p. 177-197, 2014. Disponível em: <http://www.seer. ufu.br/index.php/cdhis/article/view/28615/16640>. Acesso em: 5 out. 2015.

MARCELLO, F. A. Real versus ficção: criança, imagem e regimes de credibilidade no cinemadocumentário. Educação em Revista, Belo Horizonte, v. 26, n. 3, p. 129-150, 2010. Disponível em: <http://dx.doi.org/10.1590/S0102-46982010000300007>. Acesso em: 11 out. 2016.

MARQUES, A. C. S.; SENNA, G. A política e a estética em Lixo Extraordinário: dano, dissenso e desidentificação. Novos Olhares: revista de estudos sobre práticas de recepção a produtos midiáticos, São Paulo, v. 2, n. 2, p. 1-17, 2013. Disponível em: <http://www.revistas.usp.br/novosolhares/article/ view/69823>. Acesso em: 11 out. 2016.

PEREIRA, E. S. Isso não tem importância: eventos e sustentabilidade na sociedade do espetáculo. Communicare, São Paulo, v. 10, n. 1, p. 90-109, 2010. Disponível em: <http:/ / casperlibero.edu.br/ wp-content/uploads/2014/07/Communicare-vol.-10.1.pdf>. Acesso em: 12 out. 2016.

RAMOS, F. P. Mas afinal...: o que é mesmo documentário? São Paulo: SENAC, 2008.

TUCHERMAN, I.; CAVALCANTI, C. C. B. Um novo gênero cinematográfico: o documentário catástrofe. Revista FAMECOS, Porto Alegre, n. 35, n. 1, p. 37-43, 2008. Disponível em: <http:// www.revistas.univerciencia.org/index.php/famecos/article/view/5364/4883>. Acesso em: 12 out. 2016.

UNITED NATIONS. Report of the World Commission on Environment and Development: our common future. [S.1.], 1987. Disponível em: <http://www.un-documents.net/wced-ocf.htm>. Acesso em: 11 out. 2016. 
Marcello, F. A.; Ripoll, D.

UMA VERDADE inconveniente. Direção: Davis Guggenheim. Intérpretes: Al Gore, George Bush. [S.1.]: Paramount Pictures, 2006. 1 DVD, son.; color.

XAVIER, I. Cinema: revelação e engano. In: NOVAES, A. (Org.). O olhar. São Paulo: Companhia das Letras, 1998. p. 367-383.

Artigo recebido em 16/12/2015. Aceito em 04/02/2016.

Endereço para contato: Universidade Federal do Rio Grande do Sul, Programa de Pós-graduação em Educação, Avenida Paulo Gama, s/ $\mathrm{n}^{\circ}$, prédio 12.201, $7^{\circ}$ andar, CEP 90040-060 Porto Alegre, RS, Brasil. 